Case Report

\title{
Haemorrhagic Presentation of a Craniopharyngioma in a Pregnant Woman
}

\author{
Cesare Zoia, ${ }^{1}$ Andrea Cattalani, ${ }^{2}$ Elena Turpini, ${ }^{2}$ Viola Marta Custodi, ${ }^{1}$ Marco Benazzo, ${ }^{3}$ \\ Fabio Pagella, ${ }^{3}$ Paolo Carena, ${ }^{3}$ Elisabetta Lovati, ${ }^{4}$ Pietro Lucotti, ${ }^{4}$ and Paolo Gaetani ${ }^{1}$ \\ ${ }^{1}$ Department of Neurosurgery, IRCCS Fondazione Policlinico San Matteo, Viale Golgi 19, 27100 Pavia, Italy \\ ${ }^{2}$ Neurosurgery, Department of Clinical Surgical Diagnostic and Pediatric Science, University of Pavia, Viale Golgi 19, 27100 Pavia, Italy \\ ${ }^{3}$ Department of Otorhinolaryngology, IRCCS Fondazione Policlinico San Matteo, Viale Golgi 19, 27100 Pavia, Italy \\ ${ }^{4}$ First Department of Medicine, IRCCS Fondazione Policlinico San Matteo, Viale Golgi 19, 27100 Pavia, Italy
}

Correspondence should be addressed to Cesare Zoia; gioiaoffice@gmail.com

Received 14 May 2014; Accepted 7 July 2014; Published 5 August 2014

Academic Editor: Jorge C. Kattah

Copyright (C) 2014 Cesare Zoia et al. This is an open access article distributed under the Creative Commons Attribution License, which permits unrestricted use, distribution, and reproduction in any medium, provided the original work is properly cited.

\begin{abstract}
Objective. Craniopharyngioma is a rare tumour, and, consequently, acute clinical presentation and diagnosis, during pregnancy, of this pathology are quite difficult to find. Only few cases are reported in the literature, and no one describes these two conditions in association. Methods. We report a particular case of craniopharyngioma presenting both of the above conditions. Results. The patient was successfully operated with endoscopic technique. Conclusions. Rare and difficult cases, created by the superposition of different clinical conditions, need multidisciplinary management, with collaboration, integration, and cooperation between different medical specialists.
\end{abstract}

\section{Introduction}

Craniopharyngioma is a rare tumour, with incidence of 0,13 cases per 100,000 people/year [1], and it is the mostly benign epithelial tumour of the sellar and suprasellar region. In 1857 Zenker first described pathological findings of cells clusters similar to squamous epithelium in the hypothalamicpituitary region [2]. The term "craniopharyngioma" was coined in 1931 by Charles Frazier and further popularized by Harvey Cushing who described craniopharyngiomas as "the most formidable of intracranial tumours" [3]. Two principal patterns of craniopharyngioma are recognized: papillary and adamantinomatous. This latter pattern is made up by nests and cords of stratified squamous epithelium which are replaced by a layer of columnar cells on the outskirts, and it is characterized by the presence of dystrophic calcifications and cysts containing "motor-oil-like" fluid (brown-yellow cholesterol-rich fluid). The papillary pattern is made up by papillary squamous epithelium, and it is generally without calcifications or cysts $[4,5]$.
Acute clinical presentation of craniopharyngiomaconsisting of sudden headache, nausea, vomiting, cranial nerves palsy, decrease in visual acuity, diabetes insipidus, fever, or reduced level of consciousness-is very unusual, about $13 \%$ of all cases [6]. Within the different types of acute presentation, intratumoral haemorrhage is one of the most uncommon; in Table 1 we report the few cases of craniopharyngiomas with intratumoral haemorrhage reported in the international literature [7-18].

Even more rarely craniopharyngiomas manifest themselves with acute clinical presentation during pregnancy; from 1935 to 2013, 8 cases of craniopharyngioma during pregnancy were described in the international literature (Table 2) [19-24].

This report describes a particular case of craniopharyngioma that presents both of the above peculiarities; despite the difficulties caused by intratumoral haemorrhage and pregnancy, this tumour was treated with endoscopic miniinvasive surgery, resulting in a good and early resolution of 


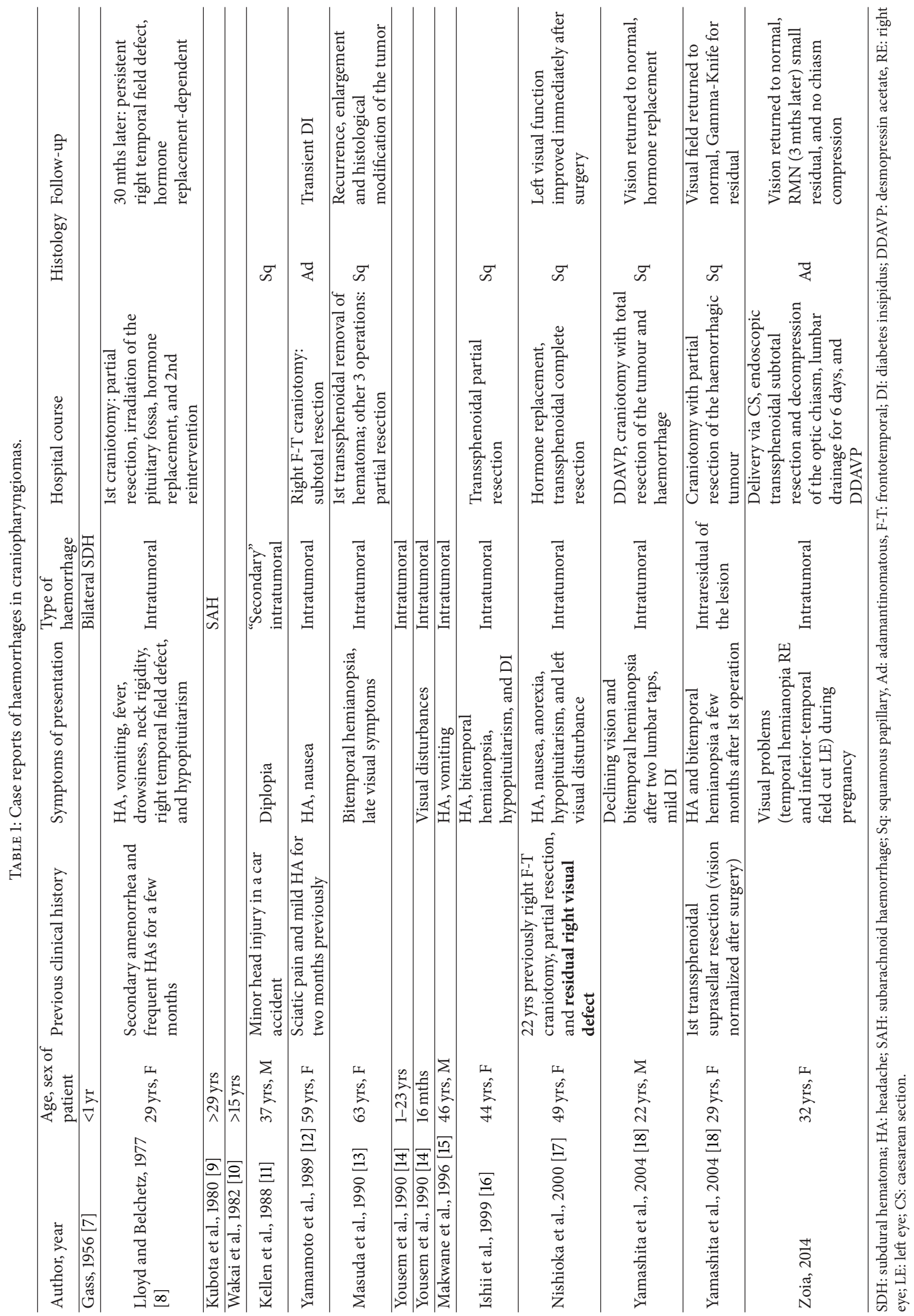


TABLE 2: Case reports of craniopharyngiomas during pregnancy.

\begin{tabular}{|c|c|c|c|c|}
\hline Authors, year & Age of patient & Symptoms of presentation & Hospital course & Follow-up \\
\hline Fischer, 1935 [19] & $?$ & $\begin{array}{l}\text { Bitemporal HA at } 20 \mathrm{wk} \\
\text { gestation }\end{array}$ & Therapeutic abortion & Patient became blind \\
\hline Sachs et al., 1978 [20] & $24 \mathrm{yrs}$ & $\begin{array}{l}\text { Visual problems and HA at } \\
28 \text { wk gestation }\end{array}$ & $\begin{array}{l}\text { Tumour resected, DDAVP } \\
\text { treatment, and normal } \\
\text { term delivery }\end{array}$ & Vision returned to normal \\
\hline Van der Wildt et al., 1980 [21] & 24 yrs & DI at 20 wk gestation & $\begin{array}{l}\text { DDAVP treatment, delivery } \\
\text { at } 36 \mathrm{wk} \text {, and tumour } \\
\text { resected postpartum }\end{array}$ & Vision returned to normal \\
\hline Hiett and Barton, 1990 [22] & $22 \mathrm{yrs}$ & $\begin{array}{l}\text { DI at } 27 \text { wk gestation, HA, } \\
\text { and visual problems }\end{array}$ & $\begin{array}{l}\text { DDAVP treatment, delivery } \\
\text { at } 34 \mathrm{wk} \text {, and tumour } \\
\text { resected postpartum }\end{array}$ & $\begin{array}{l}\text { Vision improved after } \\
\text { tumour resection }\end{array}$ \\
\hline Johnson et al., 1993 [19] & $27 \mathrm{yrs}$ & $\begin{array}{l}\text { Visual problems, HA in 2nd } \\
\text { trimester }\end{array}$ & $\begin{array}{l}\text { Tumour resection, normal } \\
\text { term delivery }\end{array}$ & $\begin{array}{l}\text { Vision near normal after } \\
\text { tumor resection }\end{array}$ \\
\hline $\begin{array}{l}\text { Maniker and Krieger, } 1996 \\
\text { [23] }\end{array}$ & 35 yrs & $\begin{array}{l}\text { Visual problems, HA at } \\
8 \text { wk gestation }\end{array}$ & $\begin{array}{l}2 \text { transsphenoidal } \\
\text { resections, healthy delivery } \\
\text { via CS at } 33 \mathrm{wk}\end{array}$ & Vision returned to normal \\
\hline Aydin et al., 1999 [25] & 19 yrs & $\begin{array}{l}\text { Visual problems and HA at } \\
20 \text { wk gestation }\end{array}$ & $\begin{array}{l}\text { Transsphenoidal resection, } \\
\text { delivery at term }\end{array}$ & $\begin{array}{l}\text { Vision returned to normal, } \\
\text { 2nd resection during } \\
\text { subsequent pregnancy } 4 \text { yrs } \\
\text { later }\end{array}$ \\
\hline Magge et al., 2001 [24] & 39 yrs & $\begin{array}{l}\text { Visual problems, DI, and } \\
\text { severe fatigue at } 6 \mathrm{wk}\end{array}$ & $\begin{array}{l}\text { Abortion, F-T craniotomy } \\
\text { with suprasellar resection, } \\
\text { and intranasal DDAVP }\end{array}$ & $\begin{array}{l}\text { Small inferior temporal } \\
\text { quadrantanopsia in LE, 2nd } \\
\text { pregnancy with new } \\
\text { bitemporal field cut that } \\
\text { disappeared after normal } \\
\text { vaginal delivery, DI in } \\
\text { treatment with DDAVP, } \\
\text { and thyroid hormone } \\
\text { replacement }\end{array}$ \\
\hline Zoia, 2014 & $32 \mathrm{yrs}$ & $\begin{array}{l}\text { Visual problems (temporal } \\
\text { hemianopsia RE and } \\
\text { inferior-temporal field cut } \\
\mathrm{LE} \text { ) at } 30 \mathrm{wk}+1 \text { gestation }\end{array}$ & $\begin{array}{l}\text { Cortisol replacement, } \\
\text { delivery via CS at } 33 \mathrm{wk}+3 \text {, } \\
\text { endoscopic transsphenoidal } \\
\text { subtotal resection and } \\
\text { decompression of the optic } \\
\text { chiasm, lumbar drainage } \\
\text { for } 6 \text { days, and DDAVP }\end{array}$ & $\begin{array}{l}\text { Vision returned to normal, } \\
\text { no hormone deficiencies; } \\
\text { RMN ( } 3 \text { months later) } \\
\text { shows small residual with } \\
\text { no chiasm compression }\end{array}$ \\
\hline
\end{tabular}

HA: headache; DI: diabetes insipidus; CS: caesarean section; F-T: frontotemporal; DDAVP: desmopressin acetate; RE: right eye; LE: left eye.

the mother's new symptoms without negative consequences for the newborn.

\section{Case Report}

The patient, a 32-year-old woman, became pregnant for the first time in her life. At the 30 weeks +1 mark of a till-then-normal pregnancy, she presented a sharp bilateral decline in visual acuity. A careful study of her clinical history only noted obesity and Hashimoto's thyroiditis treated with chronic hormone replacement. Then she was assessed by the ophthalmologist: a visual field examination (Figure 1(a)) documented temporal hemianopia in the right eye and inferiortemporal field cut in the left eye. Subsequently she underwent magnetic resonance imaging (MRI) scan, which showed an extra-axial lesion in the intra- and suprasellar regions, isointense in T1-weighted sequence (Figure 2(a)), and isohyperintense in long-TR sequences; these neuroradiological findings could be indicative of pituitary apoplexy, macroadenoma, or craniopharyngioma with signs of intratumoral haemorrhage. This clinical and radiological picture made early surgery mandatory. Neurosurgeons and obstetricians jointly evaluated the case and decided, in agreement with the patient, to postpone the operation until a more advanced gestational age to safeguard the fetal well-being. The patient underwent RDS (respiratory distress syndrome) prophylaxis and maternalfetal welfare monitoring; endocrinological examination of hormone levels confirmed diagnosis of central hypocortisolism. As a consequence the patient underwent adequate hormone replacement: Cortone Acetate $37.5 \mathrm{mg} / \mathrm{day}$. At 33 weeks +2 of gestation, the patient complained of a further decline in visual acuity; thus, she underwent a new visual field examination (Figure 1(b)) that turned out to be worse than the previous one. For this reason, after a new collegial evaluation, she underwent delivery via caesarean section (33 

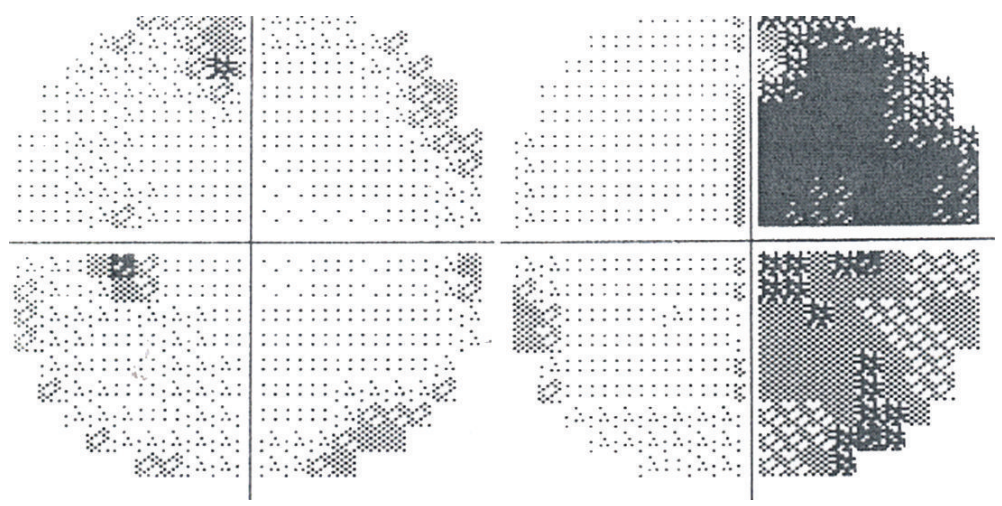

(a)
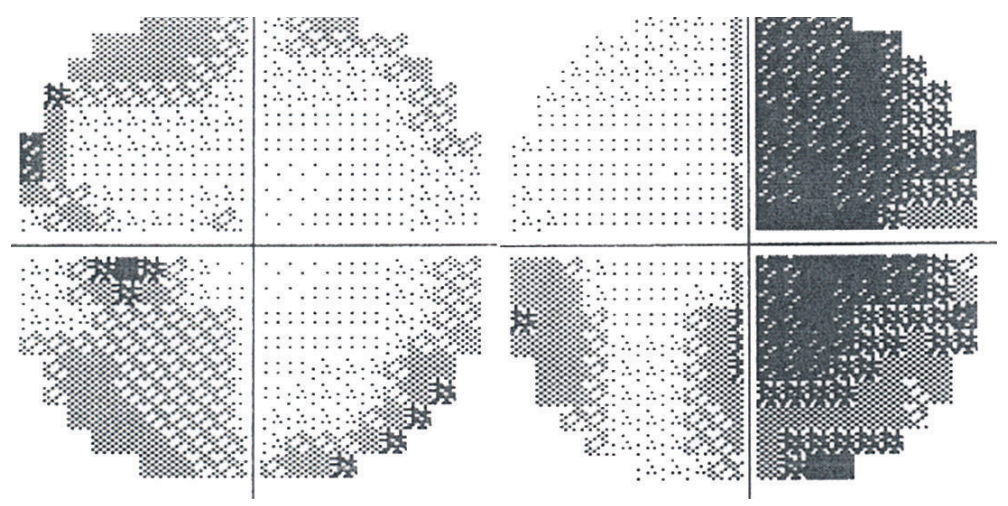

(b)
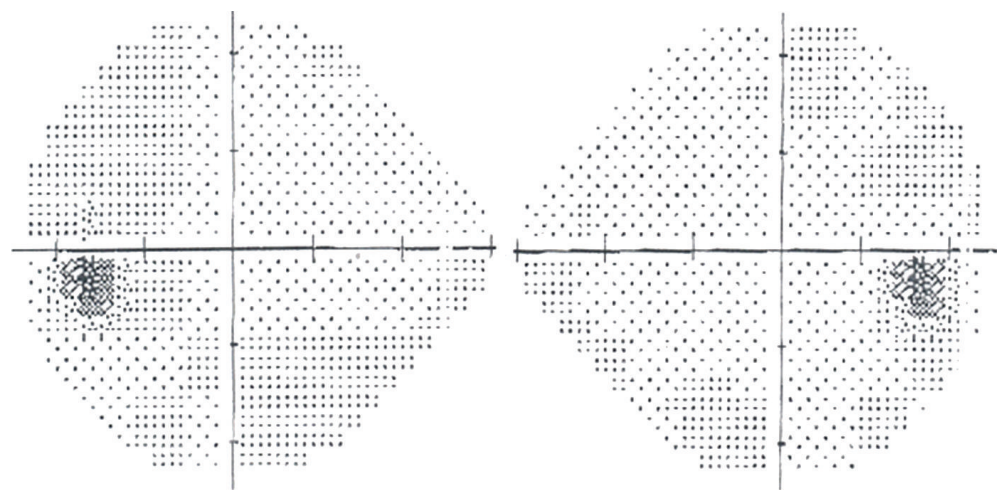

(c)

Figure 1: Onset (a), preoperative (b), and postoperative (c) visual field.

weeks +3$)$. The same day a gadolinium enhanced MRI scan was performed (Figure 2(c)), which confirmed the known sellar lesion with signs of recent intratumoral haemorrhage. The next day the patient underwent endoscopic transsphenoidal subtotal resection of the lesion and decompression of the optic chiasm. The intraoperative appearance of the lesion was that of a hard-elastic mass with fair haemorrhagic component. Histological examination of the collected material deposed for "adamantinomatous craniopharyngioma." On the VIth postoperative day, nasal liquorrhea appeared and was resolved by positioning a lumbar drainage for 6 days. Transient diabetes insipidus was treated with DDAVP (desmopressin acetate). The patient was discharged on the XVth postoperative day. Currently she is in good clinical condition and an endocrinological examination, performed one month after surgery, has excluded more hormone defects than prior to pregnancy. A visual field examination performed 2 months after surgery confirmed the resolution of the preoperative visual field defect (Figure 1(c)). An MRI scan 3 months after surgery showed a satisfactory decompression of the optic chiasm and a reduction of the tumoral mass (Figures 2(b) and 2(d)). 


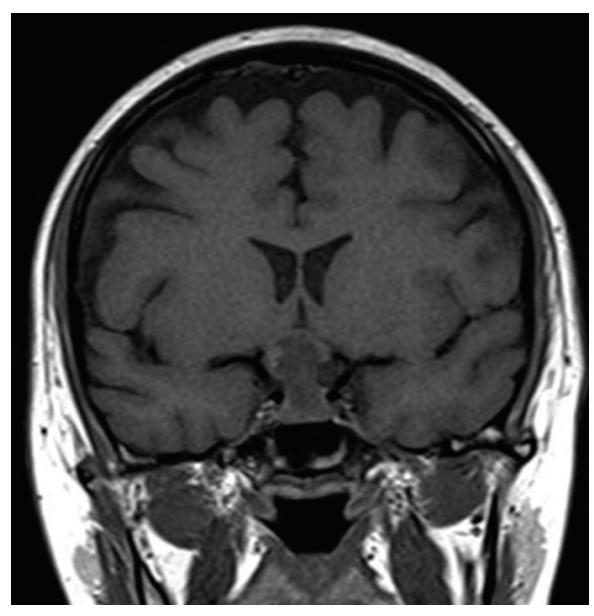

(a)

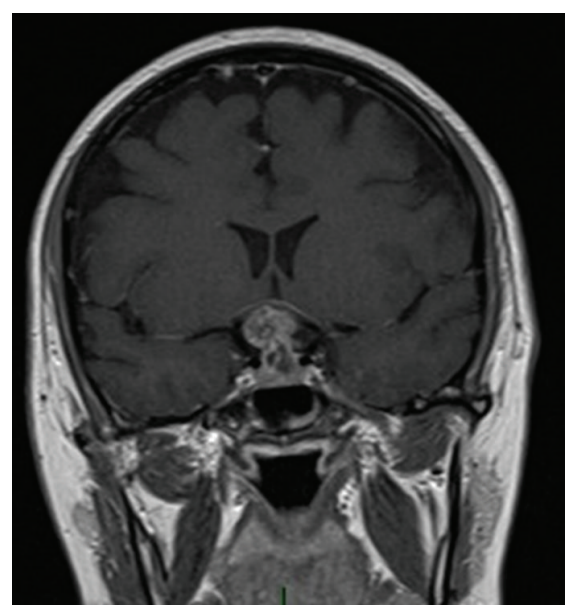

(c)

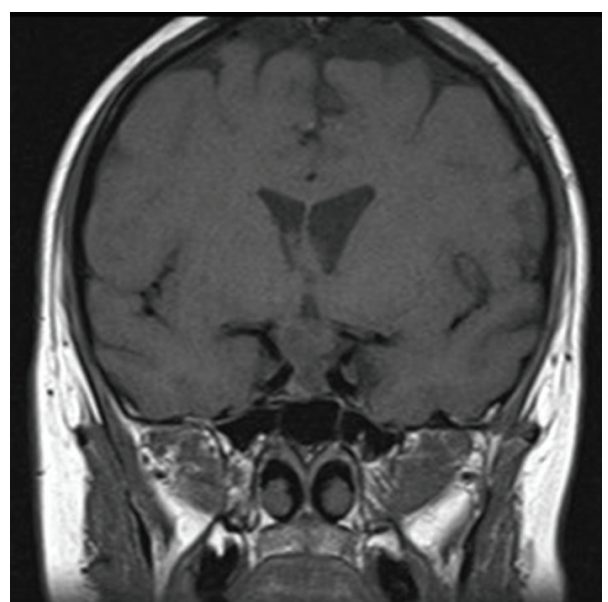

(b)

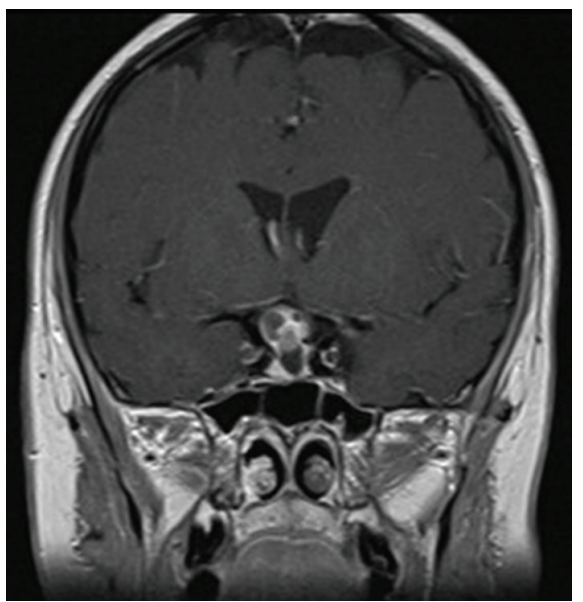

(d)

Figure 2: Coronal preoperative ((a) without gadolinium; (c) with gadolinium) and postoperative ((b) without gadolinium; (d) with gadolinium) T1 MRI.

\section{Discussion}

The international literature counts only few cases of craniopharyngiomas in pregnancy and equally few of intralesional haemorrhage cases in this kind of tumours.

As showed in Table 1, only 14 cases of craniopharyngioma with haemorrhagic presentation are reported in the literature. A considerable amount of the information contained in these articles appears to be incomplete and for this reason it is not possible to determine the average age of the patients or a gender division. In 11 cases $(78.5 \%)$ the haemorrhage was intralesional, in one case $(7.1 \%)$ it was subarachnoidal, in one case it was subdural, and in one case the type of haemorrhage was not reported. The clinical presentation was characterized by headache, nausea, and vomit in 6 cases $(42.6 \%)$, visual disturbances like diplopia, bitemporal hemianopsia, and other visual symptoms in 8 cases $(56.8 \%$,), hypopituitarism and diabetes insipidus in 4 cases $(28.4 \%)$, and neck rigidity or fever in only one case (7.1\%). Surgical treatment was transcranial in 4 cases and transnasal with endoscopic technique in 3 cases (21.3\%); in the remaining cases there is no information given about the treatment. In 3 cases $(21.3 \%)$ the visual deficit had been recovered at followup; in one case $(7.1 \%)$ the visual deficit was not recovered; in the other cases no data are given about follow-up.

As shown in Table 2, only 8 cases of craniopharyngioma presenting during pregnancy are reported in the literature. The average age of patients at diagnosis is 27.1 years and in six cases $(75 \%)$ the presentation was after the 20th week of pregnancy; only in two cases (25\%) the presentation was in the first 10 weeks of pregnancy. Symptoms of presentation were visual disturbances in 6 cases $(75 \%)$, headache in 6 cases $(75 \%)$, diabetes insipidus in three cases $(37.75 \%)$, and severe fatigue in 1 case (12.25\%). In 2 cases (25\%) therapeutic abortion was necessary and in the other 6 cases the delivery was between the 33rd and the 40th weeks (1 caesarian section). In all cases the tumour was resected: in two cases (25\%) with transnasal endoscopic technique and in 1 case $(12.25 \%)$ with a frontotemporal approach, and in the other cases neither the surgical technique nor the entity of the 
removal is reported. At follow-up, in six cases the patient had recovered the visual deficit after delivery and operation, in one case $(12.25 \%)$ the patient became blind, and in one case an inferotemporal quadrantopsy was reported.

The case we report is of particular relevance because it is the first to include both of these rarely associated clinical features. Such combination requires a multidisciplinary assessment to allow choosing the most suitable treatment from different specialistic points of view: neurosurgical, neuroradiological, endocrinological, obstetrical, gynaecological, otolaryngological, and ophthalmological.

The role of the first specialist observing the patient is crucial: his task is to correctly identify the location of the problem, in order to set an appropriate diagnostic and therapeutic plan. In the case we report, the first specialist to assess the patient was the ophthalmologist. Bitemporal hemianopia or temporal field cuts in the examination of the visual field are often suggestive of expansive lesions near the optic chiasm and sellar region. A suspicion of such nature needs neuroradiological evidence, obtainable by MRI. In this case, since the patient was pregnant, MRI was performed without contrast: it showed the presence of an extra-axial lesion in the sellar and suprasellar regions. As described by Jagannathan et al., there are many diseases that can develop in these anatomical sites: pituitary adenomas, meningiomas, metastases, abscesses, aneurysms, pituitary apoplexy, and Rathke's cleft cyst in the sellar region and aneurysms, teratomas, hypothalamic gliomas, meningiomas, and epidermoid and dermoid cysts in the suprasellar regions [26]. In the case we report, neuroradiologist formulated three diagnostic hypotheses: pituitary apoplexy, macroadenoma, or craniopharyngioma with signs of intratumoral haemorrhage. At this point, the patient was assessed by a neurosurgeon and an endocrinologist. The neurosurgeon pointed out that the patient needed a surgical intervention as soon as possible, in order to obtain adequate decompression of the optic chiasm and to treat visual impairment. The endocrinologist stressed the importance of a comprehensive study of the hormonal status, to discover and correct any subclinical deficiency. Both of them requested close collaboration with obstetrics. At first, hormonal changes during pregnancy affected the endocrinological treatment. Furthermore, intervention of the neurosurgeon was subject to the timing of delivery; despite the visual disturbances requiring treatment as soon as possible, in this case the most important elements to keep in mind were maternal well-being and fetal growth. So optic chiasm decompression was done a few hours after delivery by caesarean section. In the end, the endocrinologist also had the task of avoiding acute adrenal insufficiency in a patient subjected to two surgical stresses in a few hours. The surgery, in cooperation with ENT surgeons, was performed using the endoscopic endonasal transsphenoidal approach with the "two nostrils four hands technique" [27]. Sellar floor reconstruction was not needed.

The choice of endoscopic treatment was based on the great benefits reported by the international literature during the last years [28-38]: minimal invasiveness, reduced postoperative recovery period, and minimal psychological impact on patient, surgical outcomes, and complication rate similar to those of the classic microscopic technique.

In this case, a patient with a delicate endocrinological balance underwent 2 surgical procedures in few hours: use of endoscopic minimally invasive technique reduced the consequences of this particular surgical stress. Reduced recovery days and early ability in taking care of the newborn also resulted in the patient's more positive psychological reaction to her own disease.

In our opinion, this case represents another excellent demonstration of the versatility of the endoscopic technique, which can be used in complex clinical conditions and considered a gold standard in the surgery of the sellar and paraphrase regions.

The role of the various specialists remains important during follow-up of the patient: the ENT surgeon endoscopically checks for good repair of the wound; the neuroradiologist carries out the necessary radiological postoperative scans (CT in the early postoperative period and MRI 3 months later); the endocrinologist checks the hormonal balance and sets adequate hormone replacement; the ophthalmologist carries out field examinations in the postoperative period. Therefore, the collaboration remains critical among these different medical figures during follow-up.

\section{Conclusion}

We report what, to the best of our knowledge, is the first case in the literature in which two rare features of craniopharyngiomas overlapped at the onset; such synergistic coexistence created a clinical condition difficult to diagnose and manage.

In this particular situation, once diagnosis of sellar lesion had been obtained, all medical and surgical treatments undertaken were found to be necessary and, in particular, endoscopic minimally invasive surgery was considered the first choice. In our opinion this technique represents the gold standard in surgical approach to sellar and parasellar regions and is indispensable in cases like the reported one.

Rare and difficult cases, created by the overlapping of different clinical conditions, need multidisciplinary management, with collaboration and cooperation between many medical specialists: careful preoperative planning, minimally invasive surgery with less possible complications, and adequate follow-up are obtained only with close support and collaboration among all specialists involved.

\section{Conflict of Interests}

The authors report no conflict of interests concerning the materials or methods used in this study or findings specified in this paper.

\section{References}

[1] G. R. Bunin, T. S. Surawicz, P. A. Witman, S. Preston-Martin, F. Davis, and J. M. Bruner, "The descriptive epidemiology of craniopharyngioma," Journal of Neurosurgery, vol. 89, no. 4, pp. 547$551,1998$. 
[2] F. A. Zenker, "Enorme Cystenbildung im Gehirn, vom Hirnanhang ausgehend," Archiv für Pathologische Anatomie und Physiologie und für Klinische Medicin, vol. 12, no. 4-5, pp. 454466, 1857.

[3] G. Barkhoudarian and E. R. Laws, "Craniopharyngioma: history," Pituitary, vol. 16, no. 1, pp. 1-8, 2013.

[4] J. C. Fernandez-Miranda, P. A. Gardner, C. H. Snyderman et al., "Craniopharyngioma: a pathologic, clinical, and surgical review," Head and Neck, vol. 34, no. 7, pp. 1036-1044, 2012.

[5] V. Kumar, A. Abbas, and N. Fausto, Robbins e Cotran Le basi patologiche delle malattie, vol. 2, Elsevier, 2009.

[6] E. H. Nielsen, J. O. Jørgensen, P. Bjerre et al., "Acute presentation of craniopharyngioma in children and adults in a Danish national cohort," Pituitary, vol. 16, no. 4, pp. 528-535, 2013.

[7] H. H. GASS, "Large calcified craniopharyngioma and bilateral subdural hematomata present at birth; survey of neonatal brain tumors.", Journal of neurosurgery, vol. 13, no. 5, pp. 514-519, 1956.

[8] M. H. Lloyd and P. E. Belchetz, "The clinical features and management of pituitary apoplexy," Postgraduate Medical Journal, vol. 53, no. 616, pp. 82-85, 1977.

[9] T. Kubota, H. Fujii, K. Ikeda, H. Ito, S. Yamamoto, and I. Nakanishi, "A case of intraventricular craniopharyngioma with subarachnoid hemorrhage," Neurological Surgery, vol. 8, no. 5, pp. 495-501, 1980.

[10] S. Wakai, K. Yamakawa, S. Manaka, and K. Takakura, "Spontaneous intracranial hemorrhage caused by brain tumor: its incidence and clinical significance," Neurosurgery, vol. 10, no. 4, pp. 437-444, 1982.

[11] R. I. Kellen, R. M. Burde, and F. J. Hodges III, "Occult pituitary apoplexy associated with craniopharyngioma," Journal of Clinical Neuro-Ophthalmology, vol. 8, no. 2, pp. 99-104, 1988.

[12] T. Yamamoto, S. Yoneda, and N. Funatsu, "Spontaneous haemorrhage in craniopharyngioma," Journal of Neurology Neurosurgery and Psychiatry, vol. 52, no. 6, pp. 803-804, 1989.

[13] R. Masuda, E. Tsukamoto, S. Takeda, S. Furuichi, S. Endo, and A. Takaku, "An elderly case of recurrent craniopharyngioma suffering from hemorrhage," Neurological Surgery, vol. 18, no. 12, pp. 1151-1155, 1990.

[14] D. M. Yousem, J. A. Arrington, A. J. Kumar, and R. N. Bryan, "Bright lesions on sellar/parasellar T1-weighted scans," Clinical Imaging, vol. 14, no. 2, pp. 99-105, 1990.

[15] U. K. Makwane, A. K. Singh, V. Puri, and S. Kumar, "Primary brain tumors presenting as intra cerebral haemorrhage," Journal of Association of Physicians of India, vol. 44, no. 10, pp. 729-733, 1996.

[16] K. Ishii, M. Isono, S. Hori, Y. Kinba, and T. Mori, "A case of craniopharyngioma with intratumoral hemorrhage," Neurological Surgery, vol. 27, no. 1, pp. 73-77, 1999.

[17] H. Nishioka, H. Ito, J. Haraoka, T. Hashimoto, and Y. Kato, "Repeated hemorrhage in ciliated craniopharyngioma-case report," Neurologia Medico-Chirurgica, vol. 40, no. 6, pp. 324328,2000 .

[18] S. Yamashita, Y. Matsumoto, K. Kunishio, and S. Nagao, "Craniopharyngiomas with intratumoral hemorrhage: two case reports," Neurologia Medico-Chirurgica, vol. 44, no. 1, pp. 43-46, 2004.

[19] R. J. Johnson Jr., R. M. Voorhies, M. Witkin, A. G. Robichaux III, and W. A. Broussard Jr., "Fertility following excision of a symptomatic craniopharyngioma during pregnancy: case report," Surgical Neurology, vol. 39, no. 4, pp. 257-262, 1993.
[20] B. P. Sachs, S. K. Smith, J. Cassar, and B. van Iddekinge, "Rapid enlargement of carniopharyngioma in pregnancy," British Journal of Obstetrics and Gynaecology, vol. 85, no. 7, pp. 577-578, 1978.

[21] B. van der Wildt, J. I. M. Drayer, and T. K. A. B. Eskes, "Diabetes insipidus in pregnancy as a first sign of a craniopharyngioma," European Journal of Obstetrics Gynecology and Reproductive Biology, vol. 10, no. 4, pp. 269-274, 1980.

[22] A. K. Hiett and J. R. Barton, "Diabetes insipidus associated with craniopharyngioma in pregnancy," Obstetrics and Gynecology, vol. 76, no. 5, pp. 982-984, 1990.

[23] A. H. Maniker and A. J. Krieger, "Rapid recurrence of craniopharyngioma during pregnancy with recovery of vision: a case report," Surgical Neurology, vol. 45, no. 4, pp. 324-327, 1996.

[24] S. N. Magge, M. Brunt, and R. M. Scott, "Craniopharyngioma presenting during pregnancy 4 years after a normal magnetic resonance imaging scan: case report," Neurosurgery, vol. 49, no. 4, pp. 1014-1017, 2001.

[25] Y. Aydin, S. M. Can, A. Gǔlkilik, O. Tǔrkmenoglu, C. Alatli, and I. Ziyal, "Rapid enlargement and recurrence of a preexisting intrasellar craniopharyngioma during the course of two pregnancies: case report," Journal of Neurosurgery, vol. 91, no. 2, pp. 322-324, 1999.

[26] J. Jagannathan, A. S. Dumont, J. A. Jane Jr., and E. R. Laws Jr., "Pediatric sellar tumors: diagnostic procedures and management," Neurosurgical Focus, vol. 18, no. 6, 2005.

[27] P. Castelnuovo, A. Pistochini, and D. Locatelli, "Different surgical approaches to the sellar region: focusing on the "two nostrils four hands technique'”' Rhinology, vol. 44, no. 1, pp. 27, 2006.

[28] T. S. Higgins, C. Courtemanche, D. Karakla et al., "Analysis of transnasal endoscopic versus transseptal microscopic approach for excision of pituitary tumors," The American Journal of Rhinology, vol. 22, no. 6, pp. 649-652, 2008.

[29] B. Rotenberg, S. Tam, W. H. A. Ryu, and N. Duggal, "Microscopic versus endoscopic pituitary surgery: a systematic review," The Laryngoscope, vol. 120, no. 7, pp. 1292-1297, 2010.

[30] J. K. Goudakos, K. D. Markou, and C. Georgalas, "Endoscopic versus microscopic trans-sphenoidal pituitary surgery: a systematic review and meta-analysis," Clinical Otolaryngology, vol. 36, no. 3, pp. 212-220, 2011.

[31] A. Tabaee, V. K. Anand, Y. Barrón et al., "Endoscopic pituitary surgery: a systematic review and meta-analysis," Journal of Neurosurgery, vol. 111, no. 3, pp. 545-554, 2009.

[32] D. Y. Cho and W. R. Liau, "Comparison of endonasal endoscopic surgery and sublabial microsurgery for prolactinomas," Surgical Neurology, vol. 58, no. 6, pp. 371-375, 2002.

[33] A. R. Dehdashti, A. Ganna, K. Karabatsou, and F. Gentili, "Pure endoscopic endonasal approach for pituitary adenomas: early surgical results in 200 patients and comparison with previous microsurgical series," Neurosurgery, vol. 62, no. 5, pp. 1006-1015, 2008.

[34] H. D. Jho, "Endoscopic transsphenoidal surgery," Journal of Neuro-Oncology, vol. 54, no. 2, pp. 187-195, 2001.

[35] R. T. Netea-Maier, E. J. van Lindert, M. den Heijer et al., "Transsphenoidal pituitary surgery via the endoscopic technique: results in 35 consecutive patients with Cushing's disease," European Journal of Endocrinology, vol. 154, no. 5, pp. 675-684, 2006.

[36] B. W. O’Malley Jr., M. S. Grady, B. C. Gabel et al., "Comparison of endoscopic and microscopic removal of pituitary adenomas: 
single-surgeon experience and the learning curve.," Neurosurgical focus, vol. 25, no. 6, article E10, 2008.

[37] G. Frank, E. Pasquini, G. Farneti et al., "The endoscopic versus the traditional approach in pituitary surgery," Neuroendocrinology, vol. 83, no. 3-4, pp. 240-248, 2006.

[38] M. Berker, D. B. Hazer, T. Yü cel et al., "Complications of endoscopic surgery of the pituitary adenomas: analysis of 570 patients and review of the literature," Pituitary, vol. 15, no. 3, pp. 288-300, 2012. 


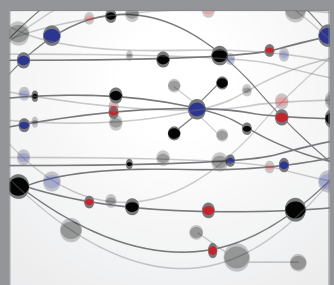

The Scientific World Journal
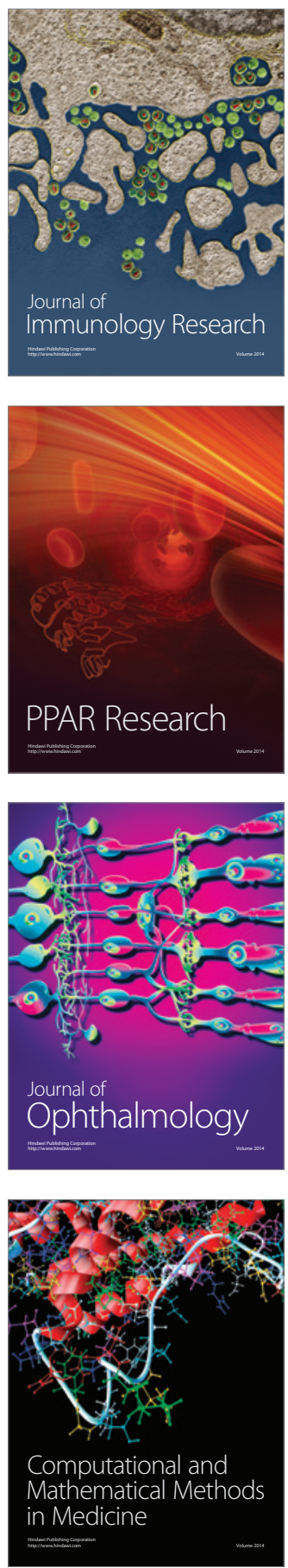

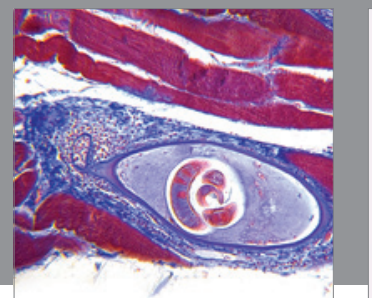

Gastroenterology

Research and Practice
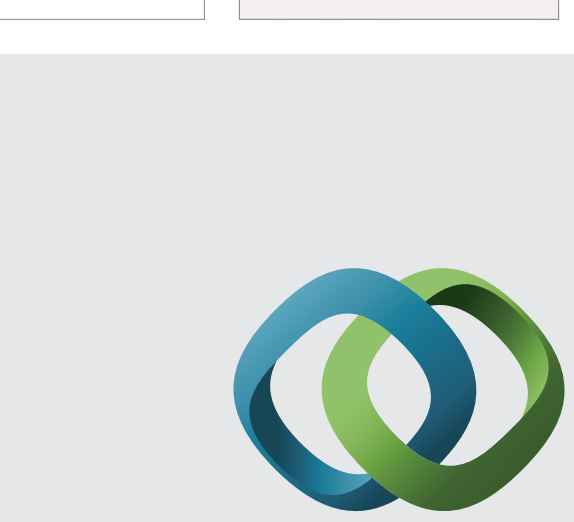

\section{Hindawi}

Submit your manuscripts at

http://www.hindawi.com
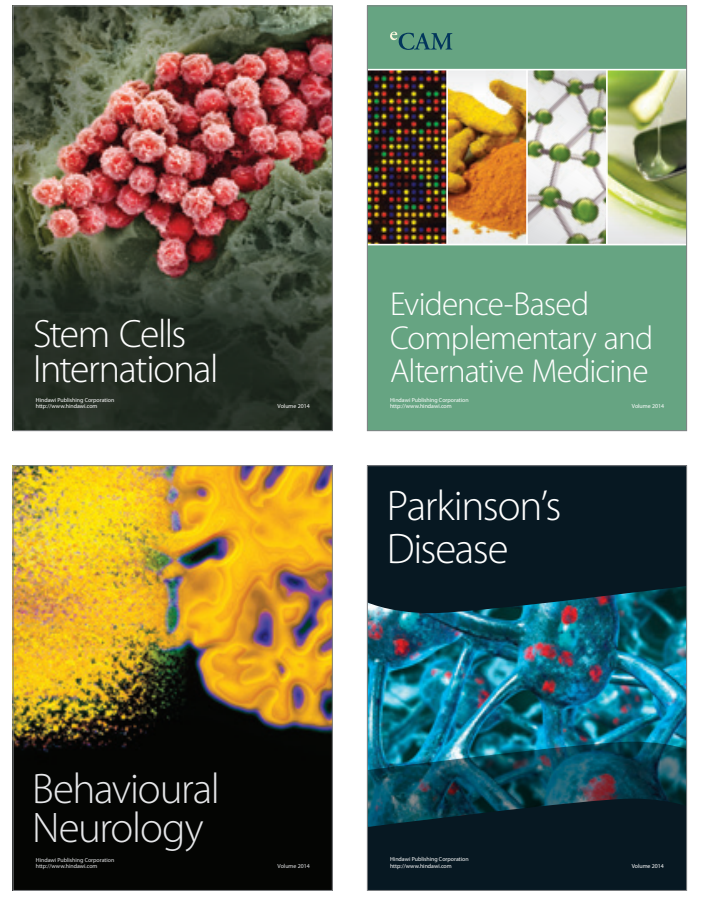
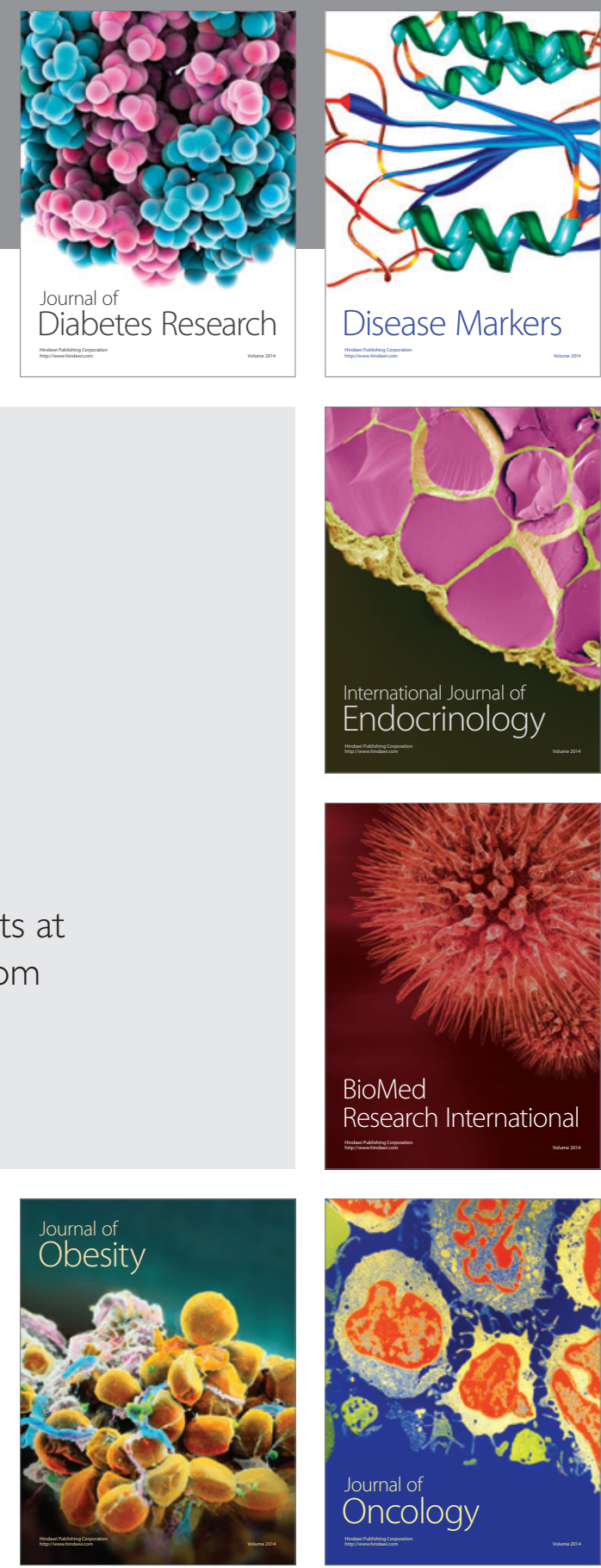

Disease Markers
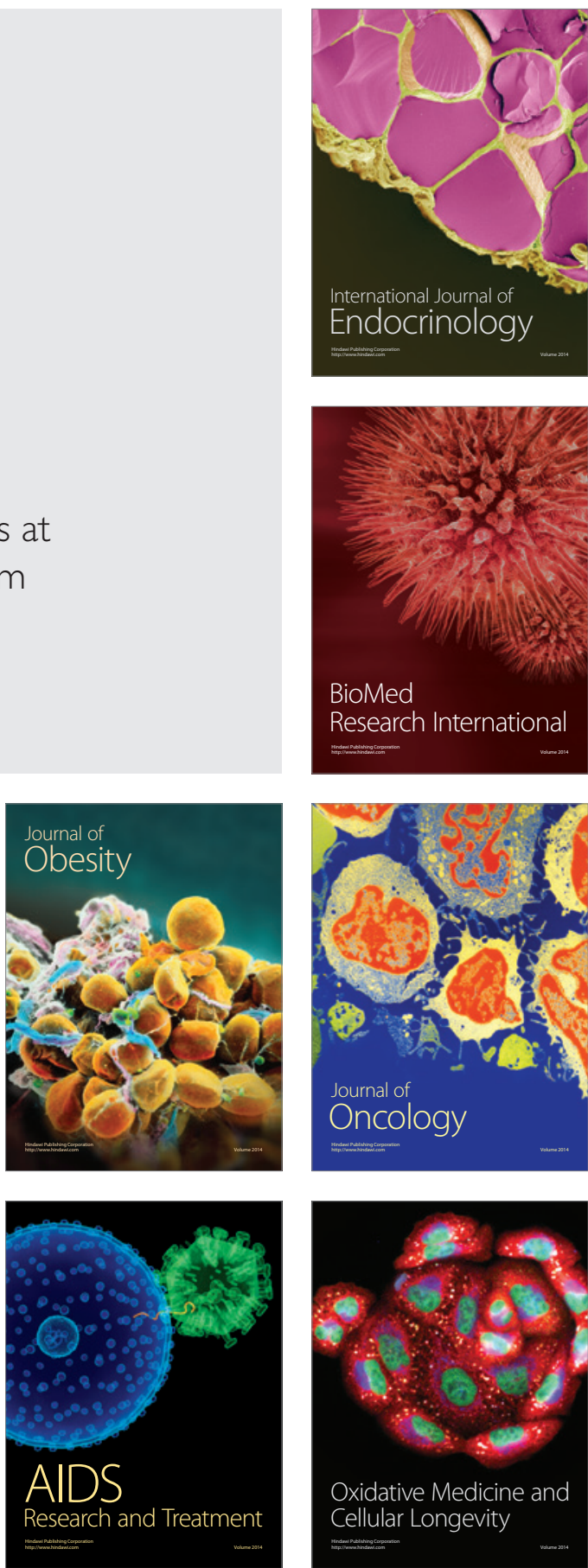